\title{
MINH TRAN HUY, Les écrivains et le fait divers. Une autre histoire de la littérature
}

\section{Francesca Forcolin}

\section{OpenEdition}

\section{Journals}

\section{Edizione digitale}

URL: https://journals.openedition.org/studifrancesi/12316

DOI: 10.4000/studifrancesi. 12316

ISSN: 2421-5856

\section{Editore}

Rosenberg \& Sellier

\section{Edizione cartacea}

Data di pubblicazione: 1 avril 2018

Paginazione: 183-184

ISSN: 0039-2944

\section{Notizia bibliografica digitale}

Francesca Forcolin, «minH TRAn hur, Les écrivains et le fait divers. Une autre histoire de la littérature», Studi Francesi [Online], 184 (LXII | I) | 2018, online dal 04 juillet 2018, consultato il 17 novembre 2021. URL: http://journals.openedition.org/studifrancesi/12316 ; DOI: https://doi.org/10.4000/studifrancesi. 12316

Questo documento è stato generato automaticamente il 17 novembre 2021.

\section{(c) $($ ) $(9)$}

Studi Francesi è distribuita con Licenza Creative Commons Attribuzione - Non commerciale - Non opere derivate 4.0 Internazionale. 


\title{
MINH TRAN HUY, Les écrivains et le fait divers. Une autre histoire de la littérature
}

\author{
Francesca Forcolin
}

\section{NOTIZIA}

MINH TRAN HUY, Les écrivains et le fait divers. Une autre histoire de la littérature, Paris, Flammarion, 2017, $318 \mathrm{pp}$.

1 L'edizione Garzanti del 2005 di A sangue freddo riporta in copertina una sintetica descrizione del capolavoro del ' 66 di Truman Capote che dice: «Resoconto giornalistico e racconto si fondono in un meccanismo narrativo perfetto». Quello che mira a essere un "romanzo giornalistico", mescolando in sé la credibilità del fatto con l'immediatezza di un film, attraverso un'implicazione in prima persona dell'autore nella vicenda narrata, ha esercitato fin dalla sua pubblicazione una grande influenza ponendosi come figura di prua del cosiddetto romanzo-documento, o giornalismo narrativo. La narrazione di un fait divers avvenuto nel cuore del Middle West agricolo attraverso l'osservazione diretta dei colpevoli, le registrazioni ufficiali e i colloqui con persone direttamente coinvolte nella vicenda, spinge TRAN HUY a interrogarsi in modo capillare e con uno stile assolutamente personale - "tutoyant" il lettore, caratteristica che si incontra piuttosto di rado nella produzione saggistica - sul fascino esercitato sui romanzieri (e in misura minore sui poeti) dai fatti di cronaca, da quegli aneddoti insoliti che rivelano un mondo dominato dall'eccesso, dall'atipico, da quelle brevi storie che colpiscono per crudeltà e violenza, rompendo con i tabù e i canoni imposti dalla morale. Per alcuni scrittori riprendere un fait divers significa investigare più da vicino su una vicenda che è già stata oggetto di narrazione (come Carrère che, in L'Adversaire, fa di Capote un modello per trattare l'«affaire» Jean-Claude Romand); altri, invece, traspongono intrigo, personaggi e circostanze sulla pagina, ricostruiscono e 
riconfigurano a partire da una storia letta o sentita; in ogni caso, la veridicità viene intesa come garanzia di qualità. Cronaca e narrazione si fondono: cosa deve dunque il fait divers alla letteratura, e viceversa? Se le origini della questione si trovano nella letteratura popolare, gran parte delle cui trame si ispiravano alla cronaca (Sue, Dumas, Féval) («Définition(s) du fait divers» pp. 13-28; «Le fait divers avant le fait divers» pp. 29-42; "Aux origines de la littérature populaire» pp. 43-58), l'espressione fa la sua comparsa per poi istituzionalizzarsi, entrando nella stampa quotidiana, intorno al 1860. Rompendo con l'usuale, l'ordinario, l'atteso, il fait divers rivela un universo capriccioso, imprevedibile, dominato dal caso, dal destino e dalla fatalità, da una logica emotiva, rinviando altresì e inaspettatamente - come l'A. sottolinea a più riprese - al mito e al suo carattere ciclico, espressione dell'immaginario collettivo e delle implicazioni socioculturali. Attirati dall'esaltazione per lo scandalo, ma trovando anche nei fatti di cronaca un pretesto per esaminare e decriptare gli ingranaggi della società e della giustizia, gli scrittori danno voce al mondo dei criminali e delle vittime servendosi della finzione attraverso un approccio documentarista, ed ergendo talvolta a idoli personaggi quali Violette Nozière - l'avvelenatrice, la patricida, la prostituta, simbolo di una femminilità isterica, incarnazione della libertà sessuale e della forza dello scandalo secondo i surrealisti, vittima degli ingranaggi sociali secondo simone de Beauvoir e Jean-Paul Sartre. Il fait divers, motore della creazione letteraria in cui la frontiera tra informazione e finzione tende a dissolversi, fornisce l'argomento del racconto, dà credibilità alla trama e rilancia l'azione. Prende dunque vita il romanzo poliziesco (Gaboriau, Simenon, Poe), che pone l'accento, diversamente dal fatto di cronaca, sull'inchiesta più che sul crimine in sé («L'esthétisation du crime ou la naissance du roman policier», pp. 59-82). La stampa e l'attualità sono allora fonte di ispirazione, informazione e idee, poiché il romanzo, a detta dei fratelli Goncourt, si costruisce a partire da documenti (raccontati), così come la Storia si fa con il materiale (scritto) («Modèle et rival du roman réaliste» pp. 83-112; «Quelques poètes du XIX ${ }^{\mathrm{e}}$ siècle» pp. 113-126). L'interesse per la cronaca nera e per il "cadavre exquis" è evidente in particolare all'inizio del $\mathrm{xx}$ secolo, quando diverse produzioni surrealiste sono caratterizzate da articoli ritagliati e incollati; e sono proprio gli esponenti di tale avanguardia a riprendere e amplificare fatti di sangue come il crimine delle sorelle Papin, le domestiche assassine («Fascination surréaliste» pp. 127-168). Da Gide a Mauriac a Camus, la riflessione sul discorso giornalistico appare evidente: basti pensare alle Caves du Vatican, la cui trama trae ispirazione da una truffa avvenuta nel 1893 ai danni di una famiglia di fervente fede cristiana; o a Camus, colpito da vicende che hanno riempito le prime pagine dei giornali dell'epoca, fornendogli materiale per la sua opera narrativa («La cours d'assises comme laboratoire» pp. 169-232). Se il desiderio di esaminare la realtà non è mai mutato, cambiato è invece nel corso dei secoli l'utilizzo di tali informazioni: fonti celate di ispirazione nel xIX secolo (Stendhal cripta le origini di Le rouge et le noir trasponendo nomi e luoghi), oggi invece vengono rivendicate. Da non dimenticare, in conclusione, l'importanza di tale pratica per dare voce a emarginati o a vittime di guerra (Le Clézio, Daeninckx) o per riprendere il discorso sulla memoria (Modiano) («Poser des mots sur le silence» pp. 233-282). Con numerosi riferimenti ad aneddoti e a opere cardine del panorama letterario dal xix secolo ad oggi, Tran Huy si muove, nel corso della sua disseminazione, con uno stile rapido e incisivo. 